\title{
In situ polymerization of styrene-clay nanocomposites and their properties
}

\author{
Lahouari Mrah $^{1}$ (D) Rachid Meghabar ${ }^{1}$
}

Received: 18 February 2020 / Revised: 1 June 2020 / Accepted: 13 June 2020 / Published online: 3 July 2020 (c) The Author(s) 2020

\begin{abstract}
This work focuses on the preparation and characterization of polystyrene/organoclay nanocomposites. The effects of the nature of the organoclays and the method of preparation were studied in order to evaluate their morphological, thermal and mechanical properties. X-ray diffraction (SAXS), Fourier transform infrared spectroscopy (FTIR), thermogravimetric analysis (TGA), scanning and transmission electron microscopy (SEM, TEM), atomic force microscope (AFM) were used to determine the characteristics of the resulting materials. Initially, cetyltrimethylammonium bromide was used as an organomodifier to modify the clay to form an organic clay. After that, polystyrene/organoclay nanocomposites were synthesized by an in situ mass polymerization process in which styrene was polymerized in the presence of different proportions of organoclay ranging from 1 to $15 \%$ by weight. The results obtained confirm the intercalation of cetyltrimethylammonium bromide (CTA) surfactant in the clay layers, while the nanocomposites obtained showed morphologies in which the exfoliated forms were obtained. Nanocomposites showed a significant improvement in thermal stability compared to unmodified polystyrene. The highlighting of the modification was examined by mechanical tests (shock, traction). The Charpy impact test showed an increase in impact resilience, and this is mainly due to a better interfacial adhesion of the matrix. The tensile test showed an improvement in stiffness.
\end{abstract}

\section{Graphic abstract}

The preparation of polystyrene-clay nanocomposites containing various amounts of organoclays ranging from 1 to $15 \%$ using the mass polymerization technique has shown the positive effect of the introduction of a cetyltrimethylammonium bromide surfactant chain on the thermal stability of the nanocomposites. Exfoliated morphologies were obtained for the majority of the prepared nanocomposites. A structure,

Extended author information available on the last page of the article 
surface and thermal property relationship was established based on TGA, XRD and TEM/SEM analyses.

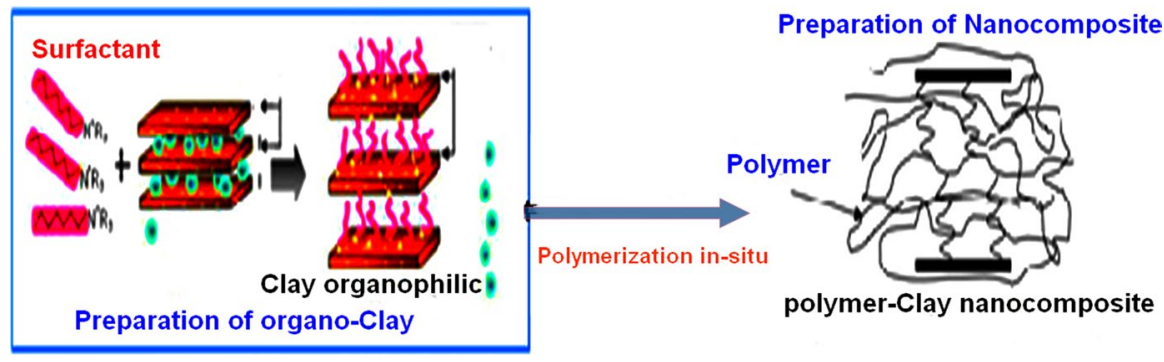

Keywords Nanocomposites · Montmorillonite $\cdot$ Cetyltrimethylammonium bromide . In situ polymerization - Characterization - Thermogravimetric analysis (TGA) · X-ray diffraction (SAXS)

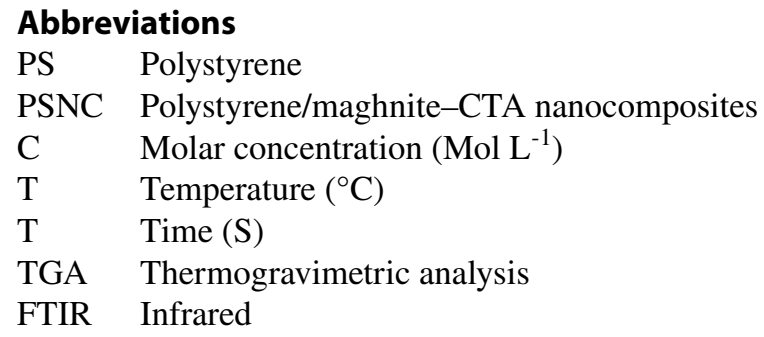

\section{Introduction}

Recent advances in materials technology have fostered the development of various preparation strategies and applications of new polymer-clay nanocomposites. Several synthesis pathways have resulted in new nanocomposites with properties that have been successfully incorporated into various application areas. Nanocomposites have attracted great interest as promising advanced materials due to their superior properties compared to conventional polymers [1,2], such as density, high resistance to surface treatment, high modulus of elasticity, nonflammability and thermomechanical/optoelectronic/magnetic properties [3-5]. Indeed, the use of a polymer matrix by adding a well-defined percentage of clay as reinforcement leads to the improvement in the physicochemical properties of the resulting nanocomposite and increase in the biodegradability of the polymer [6-10]. All these improvements depend on several parameters such as clay distribution (dimensions, shape factor, exfoliation ...) and polymer-clay interaction [7]. The improved properties of polymer-clay nanocomposites can be explained by the special properties of clays, such as swelling and ion exchange, but also by their structural nature [11]. Their twodimensional structures in lamellar form and their electronegative colloidal charge 
make them the compounds of choice for various organic molecules, including cationic surfactant molecules. The resulting hybrid materials are used in various fields such as adsorption, barrier applications and supports for the development of nanocomposites [12]. Polystyrene (PS) belongs to the group of standard thermoplastics, which also include polyethylene, polypropylene and polyvinyl chloride. Due to its special properties, PS can be used in a very wide range of applications. It is a versatile polymer with the following main characteristics: transparency, simplicity of colouring and processing and low cost [13]. The objective of this work is to prepare new polystyrene-clay nanocomposites, and we are interested in the realization of polystyrene-clay nanocomposites reinforced by the organically modified maghnite. The technique used to incorporate the modified maghnite into the polymer is polymerization in situ by intercalation of polymers in interfoliar galleries. In situ polymerization is widely used in the preparation of polymer-based nanocomposites, which tends to favour the formation of exfoliated structures. Indeed, this mode is based on the dispersion of the monomer in the clay and then its polymerization allows a better dispersion of the clay in the polymer obtained. Initially, montmorillonite is organically modified by cation exchange with the cetyltrimethylammonium bromide molecule, in order to make it organophilic. This step promotes the insertion of the organic polymers into the interpolar galleries. The method of preparation of nanocomposites is a very important parameter that has a direct impact on the structural, thermal and mechanical properties of the materials obtained.

\section{Experimental}

\section{Materials}

(S) styrene (Reagent Plus, $\geq 99 \%$ ) was supplied by BASF, and the cetyltrimethylammonium bromide noted CTA $[\mathrm{N}(\mathrm{CH} 3) 3(\mathrm{C} 16 \mathrm{H} 33)] \mathrm{Br}$ is $99 \%$ purity and was purchased from Sigma-Aldrich and used as received. Maghnite belonging to the montmorillonite family has an interlayer space of $10 \AA$ in its raw state and a cation exchange capacity $\mathrm{CEC}=90 \mathrm{meq} / 100 \mathrm{~g}$ [14].

\section{Preparation of maghnite- $\mathrm{Na}^{+}$}

Sodium ions are often chosen as compensating ions because they are more easily hydrated and promote the swelling and dispersion of montmorillonite in water. A mass of raw maghnite $(10 \mathrm{~g})$ is placed in a volume of distilled water $(40 \mathrm{ml})$, and this mixture is left in suspension under magnetic stirring and at room temperature for $2 \mathrm{~h}$. After two hours, a volume $(60 \mathrm{ml})$ of sodium chloride solution $(\mathrm{NaCl}$, $0.2 \mathrm{M}$ ) is added to the previous mixture and left to stir for $48 \mathrm{~h}$. After this time, the maghnite- $\mathrm{Na}^{+}$is filtered and washed several times with distilled water to eliminate $\mathrm{Cl}^{-}$ions. After filtration, the maghnite- $\mathrm{Na}^{+}$is dried in the oven for $24 \mathrm{~h}$ at a temperature of $105^{\circ} \mathrm{C}$, and it is then finely ground and stored in a dry place $[15,16]$. 


\section{Organic modification of clay}

Our montmorillonite has been prepared and modified according to Loïc Lepluart's protocol [17]. A quantity of $10 \mathrm{ml}$ of $1 \mathrm{~N}$ hydrochloric acid was introduced into a one-litre volumetric flask, and then the volume was filled with distilled water. Then, the solution obtained was poured into a conical flask equipped with a magnetic stirrer; this acid solution is placed at a temperature of $80^{\circ} \mathrm{C}$ used for optimized processes on a heated magnetic stirrer. When the temperature became stable, $10^{-2} \mathrm{~mol}$ of cetyltrimethylammonium bromide was introduced into the mixture. After three hours of agitation at $80^{\circ} \mathrm{C}$, the amine is dissolved and ionized. Then, $5 \mathrm{~g}$ of sodium maghnite has been added. After three hours of cation exchange, the modified maghnite was recovered and rinsed six times in a row with distilled water at $80{ }^{\circ} \mathrm{C}$ to remove mineral cations. The effectiveness of the rinsing was verified by adding a few drops of silver nitrate to the residue. Physisorbed alkylammonium ions were removed by a mixture of water and ethanol, previously heated to $75^{\circ} \mathrm{C}$. The organophilic maghnite obtained was then dried at $120^{\circ} \mathrm{C}$ and ground. This is called maghnite-CTA throughout this study [18].

\section{Composites preparation}

The bulk polymerization process used for the preparation of modified polystyrene-clay nanocomposites is based on previous work described in the literature [19, 20]. Different polystyrene-clay nanocomposites have been prepared using various amounts of modified clays corresponding to $1,3,5,10$ and $15 \%$ by weight based on the initial amount of styrene. Clay-free polystyrene was also prepared under the same conditions as standard. Each tube contained a mixture of $10.0 \mathrm{~g}$ of styrene and an amount of maghnite-CTA (1, 3, 5, 10 and 15\%); the tubes were purged with nitrogen for $20 \mathrm{~min}$ and polymerized in an oil bath at $70{ }^{\circ} \mathrm{C}$ for $72 \mathrm{~h}$ to obtain polystyrene nanocomposites (PSNC). The nanocomposites will then be denoted as PSNC1, PSNC3, PSNC5, PSNC10 and PSNC15 according to their containing clay [21].

\section{Characterization}

The small-angle X-ray diffraction apparatus (SAXS) consists of an X-ray source with a wavelength of $=0.1371 \mathrm{~nm}$ (Bruker-D8 advance AXS, $40 \mathrm{kV}, 40 \mathrm{KA})$. The infrared spectra were drawn on a Perkin Elmer IR TWO spectrophotometer equipped with an ATR, in the range $400-4000 \mathrm{~cm}^{-1}$. The thermogravimetry (TG) technique was also used, by means of TGA 51 Shimadzu equipment, operating at a heating rate of $25{ }^{\circ} \mathrm{C} \mathrm{min}^{-1}$, from room temperature up to $900{ }^{\circ} \mathrm{C}$ under an air atmosphere with a flow rate of $50 \mathrm{~mL} \mathrm{~min}^{-1}$. The sample mass was $5.0 \pm 0.5 \mathrm{mg}$. Scanning electron microscopy (SEM) is an electron microscopy technique based on the principle of electron-matter interactions JEOL JSM-6340F. The phase morphologies of the nanocomposites were thus observed with the transmission electron microscope 
(TEM), Philips CM 120, operating at an accelerating voltage of $120 \mathrm{kV}$. The topographic study of surfaces generally allows extracting information on the growth of thin films and especially of oxide layers. The near-field microscope "JSPM-4200" is calibrated in contact or tapping mode, according to the standard called the reference standard or metal grid, and using the magneto-optical Kerr effect. Remember that there is often a problem of resolution in atomic force microscopy (AFM), because of the size of the probe. The Charpy impact test was performed on a Zwick/Roell machine with a sheep7.5 J free-fall pendulum, on samples of $15 \mathrm{~mm}^{2}$ cross section. For each sample, five tests were performed to determine an average value of the impact resistance. The tensile tests were carried out on a Zwick/Z010 machine; this dynamometer connected to an acquisition chain allows the simultaneous recording of time, load displacement and deformation. The information is stored and processed by computer using TestXpert V 9.01 software, using five test specimens for each dumbbell-shaped sample in accordance with ASTMD 638-II. The deformation rate $v$ is between 1 and $50 \mathrm{~mm} / \mathrm{min}$ ).

\section{Results and discussion}

This simple analysis technique allows us to easily highlight the presence of surfactant molecules in the montmorillonite gallery, based on the comparison of the different absorption bands of functional groups present in the clay before and after its modification. The spectra of the organophilic maghnites (Mag-CTA) show the appearance of new peaks that indicate the insertion of alkylamines in the interleaving galleries of our clays. The analysis of these spectra shows the main absorption bands of the vibration modes of the different functional groups. An absorption band centred on $3620 \mathrm{~cm}^{-1}$ is due to the valence vibrations of the $\mathrm{OH}$ groups linked to the octahedral cations $\mathrm{Al}(\mathrm{Al}-\mathrm{OH}-\mathrm{Al})$ [22] and the band at $3440 \mathrm{~cm}^{-1}$ which is due to the $\mathrm{OH}-\mathrm{Fe}^{+3}$ valence vibrations which widens the adsorption band. The band centred at $1642 \mathrm{~cm}^{-1}$ is attributed to the $\mathrm{H}-\mathrm{O}-\mathrm{H}$ deformation vibrations of water molecules. The adsorption bands from 1000 to $500 \mathrm{~cm}^{-1}$ are attributed to the valence and deformation vibrations of octahedral ions substituted for hydroxyl groups and the intense band observed at $1030 \mathrm{~cm}^{-1}$ which corresponds to the valence vibrations of the $\mathrm{Si}-\mathrm{O}$ bond in the plane [23]. The bands centred at $915,865,792,624,520 \mathrm{~cm}^{-1}$ are attributed, respectively, to the deformation vibrations of the $\mathrm{Al}-\mathrm{OH}-\mathrm{AL}, \mathrm{Si}-\mathrm{O}-\mathrm{Al} / \mathrm{Al}-\mathrm{OH}-\mathrm{Mg}$, cristobalite, $\mathrm{Si}-\mathrm{O}-\mathrm{Mg}$ and $\mathrm{Mg}-\mathrm{OH}$ bonds [24]. Figure 1 shows the FTIR spectra of the welded maghnites; examination of these spectra shows: as in the maghnite spectrum, there are two bands characteristic of the valence vibrations of the $\mathrm{OH}$ groups of the octahedral layer $\left(3626 \mathrm{~cm}^{-1}\right)$ and the $\mathrm{OH}-\mathrm{Fe}^{+3}$ valence vibrations $\left(3445 \mathrm{~cm}^{-1}\right)$ : the characteristic band with $\mathrm{H}-\mathrm{O}-\mathrm{H}$ deformation vibrations of water molecules $\left(1637 \mathrm{~cm}^{-1}\right)$ and the band corresponding to the valence vibrations of the $\mathrm{Si}-\mathrm{O}$ bond (located between 1000 and $500 \mathrm{~cm}^{-1}$ and centred around $1034 \mathrm{~cm}^{-1}$ ). The spectrum of sodium montmorillonite also illustrates characteristic bands to the deformation vibrations related to substitutions in the octahedral layer (between 920 and $525 \mathrm{~cm}^{-1}$ ). The spectra of organophilic maghnite 


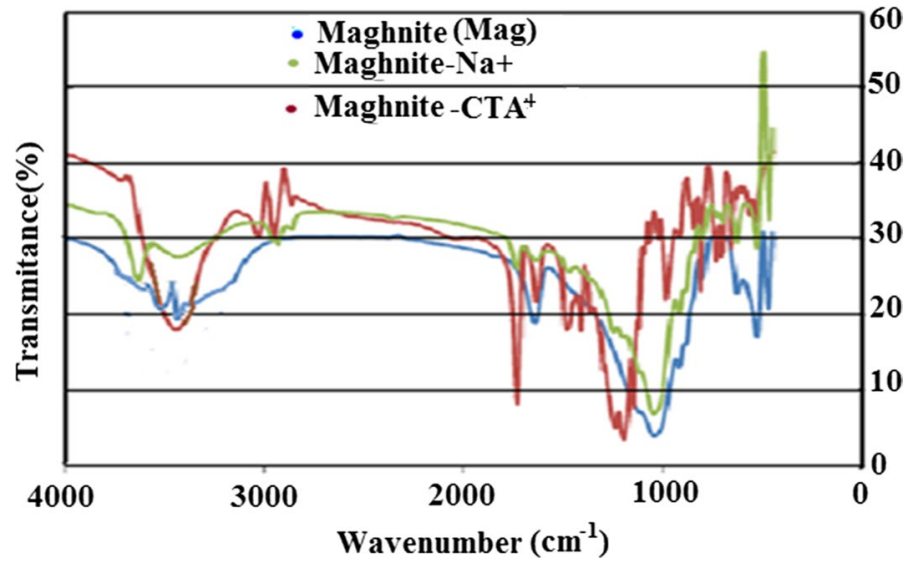

Fig. 1 Infrared spectrum of raw maghnite, Mag-Na ${ }^{+}$and Mag-CTA

(Mag-CTA) show the appearance of new peaks that indicate the insertion of alkylamines into the interfoliary galleries of our clays. These peaks are attributed to the valence and deformation vibrations of the different alkylamine groups. This band is slightly shifted (Fig. 1) and may be due to an interaction between the carbonyl function of the surfactant and the clay surface and more probably via the establishment of hydrogen bonds with hydroxyl groups located at the extreme surface of the clay. These vibration modes are $\mathrm{CH}_{2}$ valence vibrations between 2950 and $2850 \mathrm{~cm}^{-1}$, shear vibrations between 1470 and $1450 \mathrm{~cm}^{-1}$ and swing vibrations between 600 and $650 \mathrm{~cm}^{-1}$; this indicates that the organic group is present with maghnite [25]. All the FTIR spectra of the prepared organoclays confirm the incorporation of surfactants into the clay.

The different characteristic bands and their attributions are grouped in Table 1.

The FTIR spectra of the nanocomposites obtained by mass polymerization are almost identical and contain both the characteristic absorption bands of polystyrene and modified clay (Fig. 2). The different characteristic bands of PS, PS/Mag- $\mathrm{Na}^{+}$ and PS/Mag-CTA and their allocations are grouped in Table 1. The absorption

Table 1 FTIR bands characteristic of PS and PS/Mag- $\mathrm{Na}^{+}$and PS/maghnite nanocomposite containing 3 wt \% clay

\begin{tabular}{llll}
\hline Functional groups & Frequency $\left(\mathrm{cm}^{-1}\right)$ PS & $\begin{array}{l}\text { Frequency }\left(\mathrm{cm}^{-1}\right) \text { PS/ } \\
\text { Mag-Na }\end{array}$ & $\begin{array}{l}\text { Frequency } \\
\left(\mathrm{cm}^{-1}\right) \text { PS/Mag- } \\
\text { CTA }^{+}\end{array}$ \\
\hline $\mathrm{Al}-\mathrm{O}$ & & 615 & 635 \\
$\mathrm{Si}-\mathrm{O}$ & & $460,525,1035$ & $462,522,1032$ \\
$-\mathrm{CH} 2$ & 1440,1490 & $1460-1491$ & 1450,1482 \\
$\mathrm{C}=\mathrm{C}$ & $1761-1940$ & $1725-1966$ & $1731-1947$ \\
$\mathrm{C}-\mathrm{H}$ & 2843,2932 & 2940,3045 & 2851,2924 \\
$\mathrm{O}-\mathrm{H}$ & & $1668,3453,3655$ & $1665,3476,3618$ \\
$\mathrm{Ar}-\mathrm{H}$ & $3025,3060,3083$ & $3015,3030,3060$ & $1666,3450,3635$ \\
\hline
\end{tabular}


Fig. 2 Infrared spectrum of PS, $\mathrm{PS} / \mathrm{Mag}-\mathrm{Na}^{+}$and PSNC

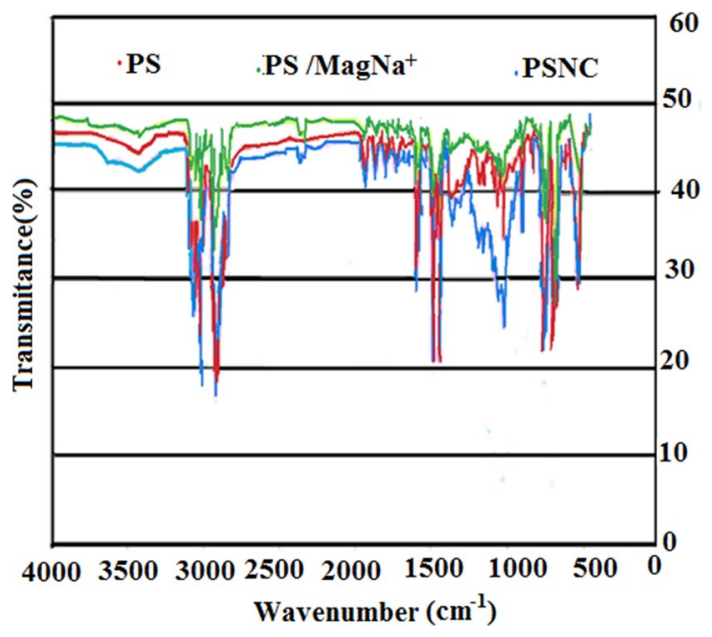

bands characterizing the Mag-CTA and PS groups are present in the spectrum of PS nanocomposites such that the absorption band of the $\mathrm{C}-\mathrm{H}$ range of the $-\mathrm{CH}_{3}$ end groups appears between 2843 and $2949 \mathrm{~cm}^{-1}$ and that of the $\mathrm{CH}_{2}$ groups of PS and Mag-CTA appears between 1450 and $1482 \mathrm{~cm}^{-1}$. The $3622 \mathrm{~cm}^{-1}$ band characterizing the free $\mathrm{OH}$ groups of the octahedral layers of Mag-CTA disappears in the PSNC nanocomposite, showing that interactions between PS and Mag-CTA chains are possible. This confirms the incorporation of CTA clay in polystyrene matrices.

The basal spacings (interlayer distance) of the raw clay (Mag), clay treated with $\mathrm{NaCl}\left(\mathrm{Mag}-\mathrm{Na}^{+}\right)$, organophilic montmorillonite $\left(\mathrm{Mag}-\mathrm{CTA}^{+}\right)$and their nanocomposites with PS were obtained from the peak position of the XRD pattern. The interfoliar distance of $\mathrm{Mag}-\mathrm{Na}^{+}$increased from 12.27 to $33.53 \AA$ for the prepared MagCTA, which corresponds to a bimodal profile, centred on two values of $19.27 \AA$ and $33.53 \AA$ (Fig. 3). The high relative peak intensity in the (001) plane is due to a narrower distribution of the interlamellar spacing when the CTA ions are incorporated into the clay sheets. Several (001) basal reflections can be observed, corresponding to the crystallographic planes of the clay layer (110) and (020) [26] and its position being independent of the basal spacing.

Mass polymerization has shown that this mode of synthesis seems to favour the exfoliated morphology with the exception of PSNC15\% nanocomposites, which will lead to an intercalated structure (presence of a peak at $2 \theta=5.88^{\circ}$ ). The basal reflection (001) of the Mag-CTA has totally disappeared. Figure 4 shows the SAXS spectra of PSNC nanocomposites obtained by adding different percentages by weight of modified clay to styrene, while 1 and $10 \%$ nanocomposites give exfoliated morphologies (Table 2). The PSNC15\% nanocomposite tends to have a morphology intercalated with a slight displacement of the basal distance of $2 \theta=5.8^{\circ}$ smaller compared to the organoclay used $\left(2 \theta=5.2^{\circ}\right)$. This result indicates that the clay has kept its orderly state with a small amount of polystyrene between the layers of the clay. This effect has already been noted during the intercalation of polymerizable surfactants in clay and has been explained by a "pinning" effect of the clay layers following the 


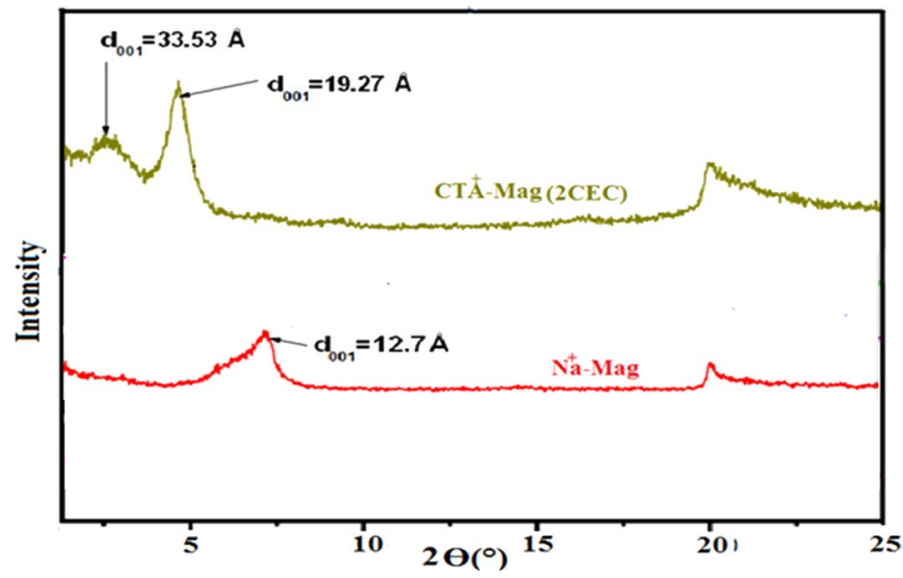

Fig. 3 Patterns of the maghnite- $\mathrm{Na}^{+}$, maghnite-CTA

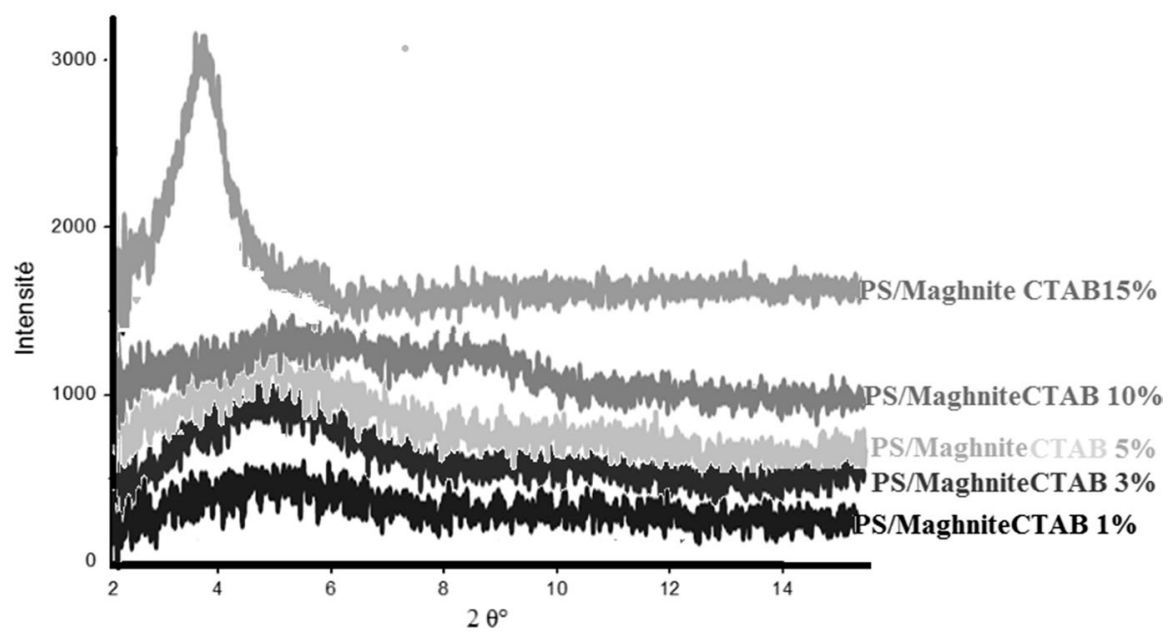

Fig. 4 XRD spectra of PS/maghnite-CTA nanocomposites at (1, 3, 10 and 15\%)

Table 2 Morphology of nanocomposites PS/Mag-CTA ${ }^{+}$

\begin{tabular}{lll}
\hline Nanocomposites & $\begin{array}{l}\text { Morphology of nanocom- } \\
\text { posite }\end{array}$ & $d_{001}\left(\mathrm{~A}^{\circ}\right)$ \\
\hline Mag_CTA $^{+}$ & Exfoliated & 33.53 \\
PPON1C1\% & Exfoliated & - \\
PPON1C3\% & Exfoliated & - \\
PPON1C5\% & Exfoliated & - \\
PPON1C10\% & Intercalated & - \\
PPON1C15\% & & 34,6 \\
\hline
\end{tabular}


reaction of growing polystyrene chains with several polymerizable surfactant molecules present on the surface of the clay, which induces a narrowing of the lamellar structure and thus a slight decrease in the basal space while maintaining the ordered structure of the clay [27-29]. The 10\% composite has an intermediate behaviour; in fact, its DRX diffractometer has a broad peak towards $2 \theta=3.5^{\circ}$, which can be interpreted either by partial exfoliation or by a disorder in the tactoids of clay [30]. Note that for 10 and $15 \%$ nanocomposites, there is a small peak at $2 \theta=2.1^{\circ}$ which corresponds to the presence of small occasional tactoids. This behaviour is often observed when using long-chain alkyl surfactants as clay modifiers [31].

Transmission electron microscopy is the most widely used qualitative technique for the characterization of polymer-clay nanocomposite dispersions. Figure 5a, b, $\mathrm{c}$ of the PSNC\% nanocomposites shows a degree of disorder in the morphology of the clay. The dark lines correspond to the silicate monolayers, and the clay platelets are separated from each other, which is in favour of an exfoliated structure. The silicate nanoplaquettes are oriented more or less parallel to each other but are separated enough from each other so that they do not interact. The TEM image of the PSNC $15 \%$ nanocomposite (d) shows an intercalated morphology, which corresponds to the results found by DRX with the presence of small tactoids. Indeed, in addition to the exfoliated nanoplaquettes, we note the presence of some aggregates.

Figure 6 shows the SEM images obtained for the nanocomposites PSNC1\%, PSNC3\%, PSNC5\% PSNC7\%. The micrographs of the PSNC nanocomposite show

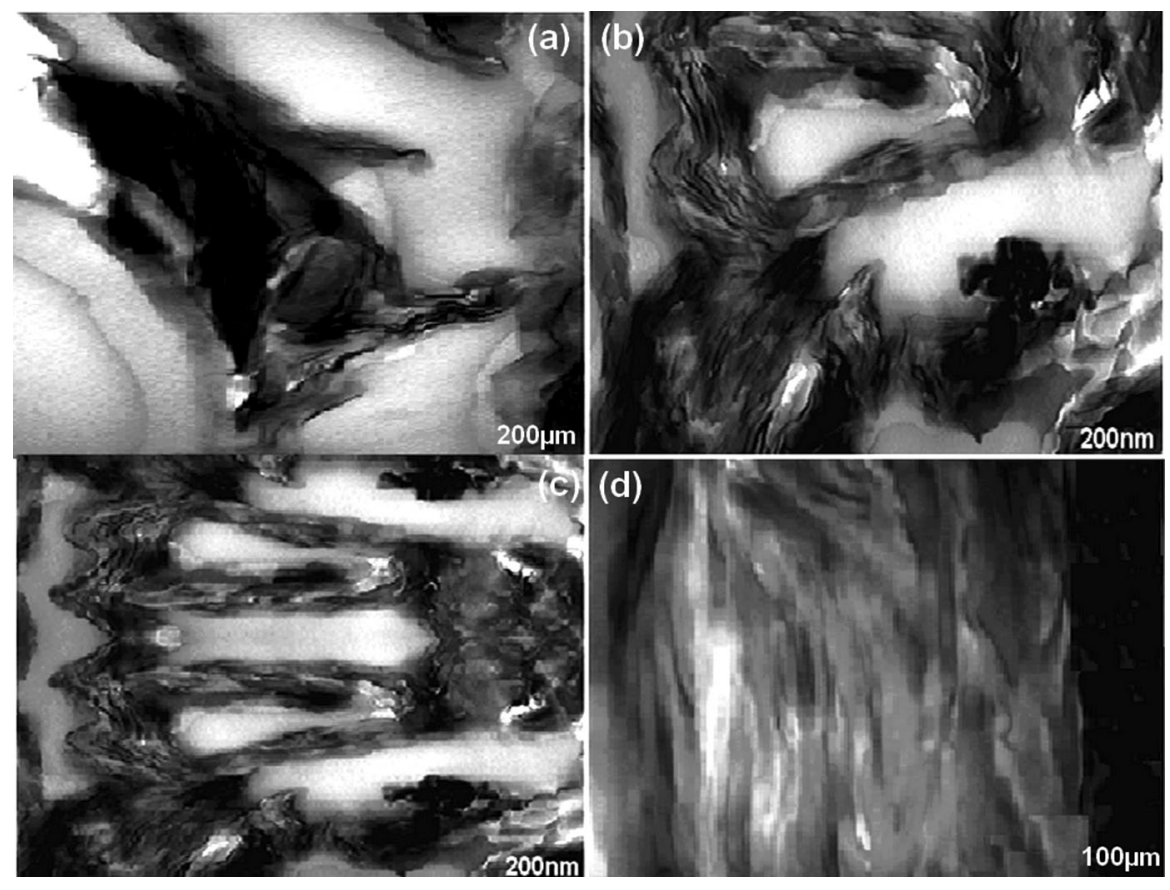

Fig. 5 TEM images of: a PSNC1 (exfoliated), b PSNC5 (exfoliated), PSNC10 (exfoliated) and d PSNC5 (intercalated) 


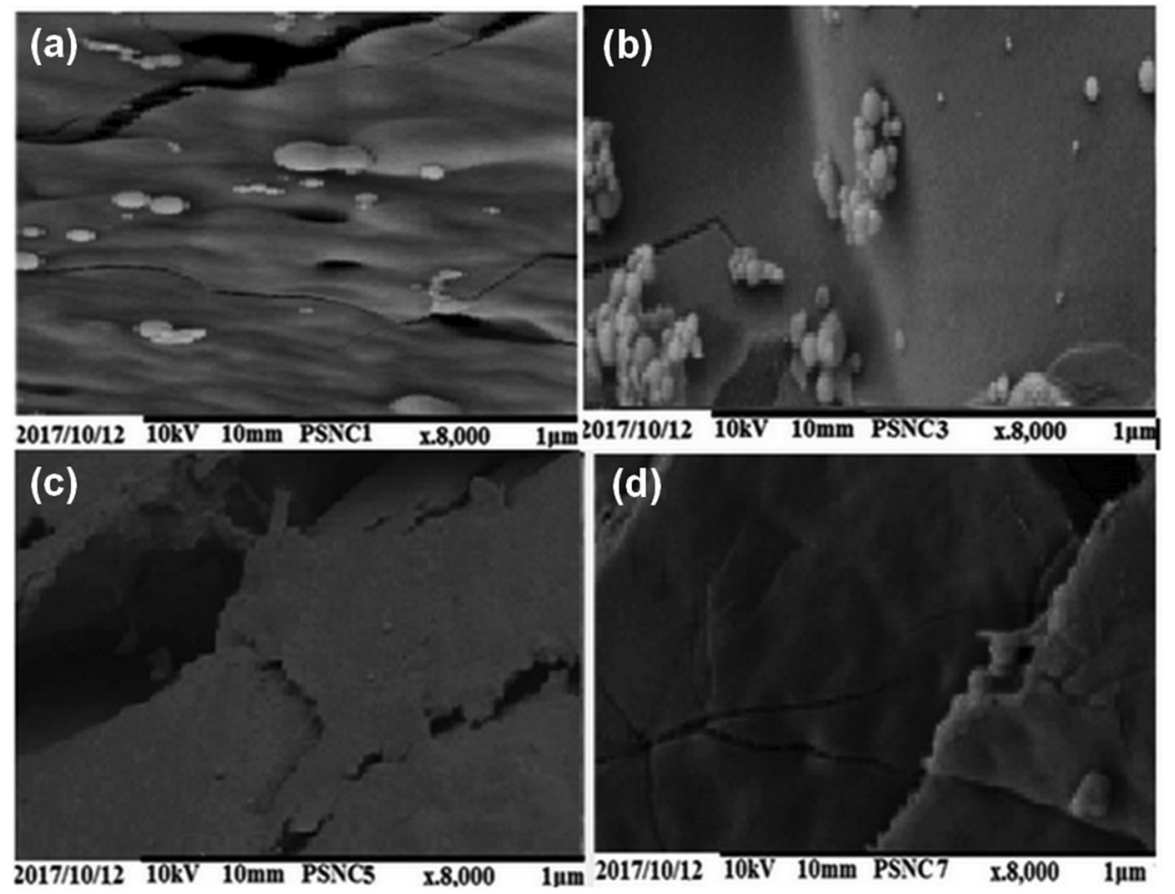

Fig. 6 SEM image of a PSNC1\%, b PSNC3\%, c PSNC5\%, d PSNC7\% nanocomposites

the presence of tortuous fissure propagation lines leading to a porous appearance, and comparison of the images shows that as the amount of organoclay dispersed in the PS matrix increases, the appearance of the nanocomposite becomes more irregular and porous. It has been described in the literature that when silicate polymers are well dispersed, many nonlinear cracks are formed and tend to develop until they interfere with each other [32]. Stresses at the ends of fracture lines interact with each other and hinder the growth of these stresses. Since the strength of the polymeric material is closely related to crack formation at the molecular level, the greater the number of these tortuous cracks during the failure process, the more energy will have to be absorbed to break the material.

The AFM characterization also gives the value of the RMS (root-mean-square) roughness and the average roughness $\mathrm{Ra}$ of the surface of each layer analysed. These two roughnesses are given by the relationships V.1 and V.2.

$$
R M S=\frac{\sqrt{\sum_{i j}(Z i j-\langle Z\rangle)^{2}}}{N}
$$

The RMS roughness is the average of the distance differences between the altitude $z$ of each point and the average altitude of the line. The average roughness is given by: 


$$
R a=\frac{\sum_{i j}[Z i j-\langle Z\rangle]}{N}
$$

It is the average of the differences between the attitudes $z$ of each point on the line and the value of the average attitude with $\langle Z\rangle=\frac{\sum_{i j} Z i j}{N}$

The AFM image processing software directly gives the value of the RMS and Ra roughness. Figure7 shows how the roughness varies as a function of Load rate by weight $\%$. The roughness values indicate that the surfaces have slightly more hollow profiles and the decrease in roughness of the sample is related to the decrease in grain size, thus making the surface less rough; the variation in roughness follows the variation in load rate by weight. It can be seen that the PSNC5 nanocomposites have the lowest roughness values. This is due to the exfoliation of the PS/Mag-CTA nanocomposite. Comparison of the images shows that as the organic clay dispersed in the PS matrix increases, the appearance of the nanocomposite becomes more irregular and porous. Many nonlinear cracks form and tend to grow until they interfere with each other. This change in clay particle size was observed by SEM on samples PSNC1, PSNC3, PSNC5 and PSNC7.

Figure 8 shows a micrograph to the right of a morphological examination of $5 \mu \mathrm{m} \times 5 \mu \mathrm{m}$. The surface of a PSCN in real space has three dimensions to see the shape of the reliefs. The one on the left evokes the observation of this surface in 2D but with the calculation of depth $Z$ of these reliefs, which could not be seen on the photographs of the SEM, on the micrograph of PSNC nanocomposites, the layers are smooth with a significant roughness; we can clearly see that the light areas are higher and the dark areas deeper; these two areas appear better on the 3D micrograph.

The thermal stability of nanocomposites has been studied by thermogravimetric analysis; these results show that the thermal stability of prepared nanocomposites is not only related to the clay content, but is also much more related to the condition of the clay in the polymeric matrix, on the surface between the polymeric matrix and the clay. The addition of only $1 \%$ modified clay improves the degradation

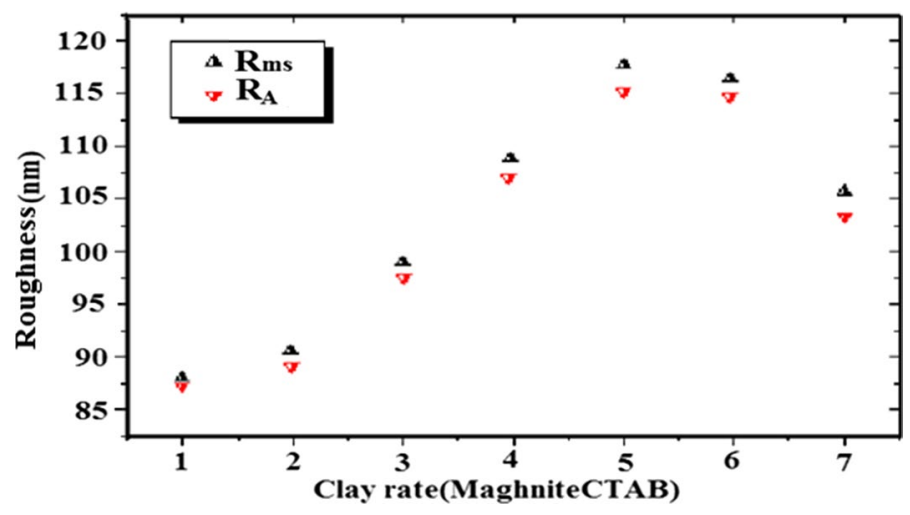

Fig. 7 Variation in surface roughness as a function of the loading rate by weight $\%$ of the sample 
Table 3 TGA results of pure PS and $\mathrm{PSNC} \%$

\begin{tabular}{lll}
\hline & $T$ at 20\% degradation $\left({ }^{\circ} \mathrm{C}\right)$ & $\begin{array}{l}T \text { at 50\% } \\
\text { degradation } \\
\left({ }^{\circ} \mathrm{C}\right)\end{array}$ \\
\hline PS & 347 & 381 \\
PSNC1\% & 353 & 390 \\
PSNC3\% & 396 & 403.2 \\
PSNC5\% & 405 & 435 \\
\hline
\end{tabular}
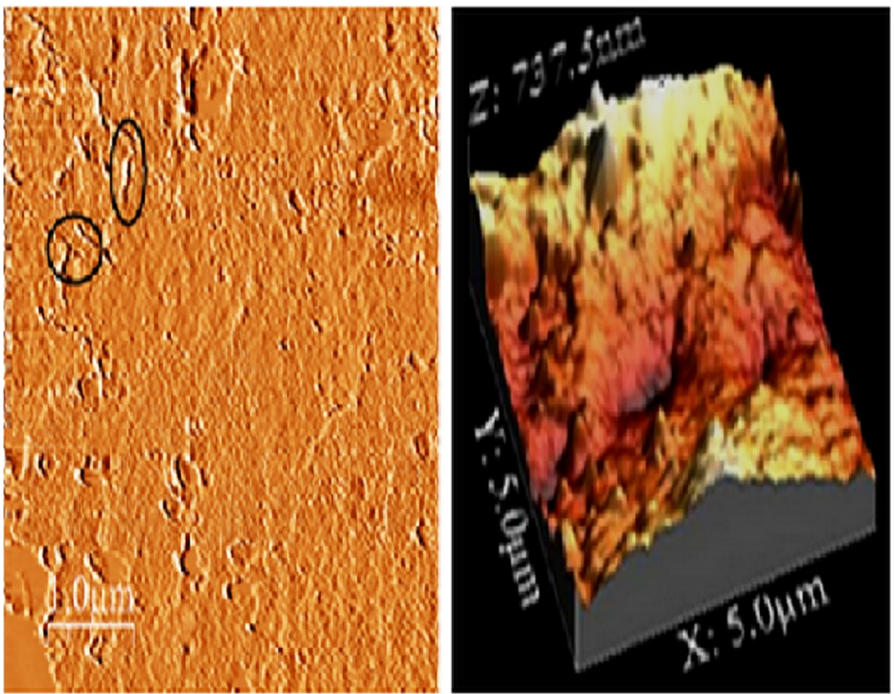

Fig. 8 AFM images of nanocomposite PSNC3\% $(5 \mu \mathrm{m} \times 5 \mu \mathrm{m})$

temperatures $T_{20}$ and $T_{50}$ by $6{ }^{\circ} \mathrm{C}$ and $10{ }^{\circ} \mathrm{C}$, respectively, compared to polystyrene. Above a concentration of $5 \%$, there is little difference between the degradation profiles suggesting a threshold effect. The thermal stability of the PS/Mag-CTA nanocomposites obtained by incorporating 1, 5, 3\% by weight of Mag-CTA-based organoclay with respect to styrene has been determined. The data obtained are grouped in Table 3 and Figure 9.

This result is in agreement with those reported in similar research studies where the authors generally observe an increase in the degradation temperature of nanocomposites due to good polymer-clay interactions or clay platelets slow the diffusion of degradation products. Zang et al. [33] described the synthesis of three quaternary polystyrene ammonium surfactants for the modification of montmorillonite. Clay modified by reaction with chloromethyl polystyrene gives the most thermally stable nanocomposites. Essawy et al. [34] observed that PS-clay nanocomposites modified with cetylpyridinium chloride were stable above $400{ }^{\circ} \mathrm{C}$ compared to PS and PS-clay nanocomposites modified by CTA. Uthirakumar et al. [35] showed an increase in the temperature at the beginning of degradation of nearly $35^{\circ} \mathrm{C}$ by 
Fig. 9 TGA curve of PSNC containing different quantities of Mag-CTA organoclay from 25 to $880{ }^{\circ} \mathrm{C}$

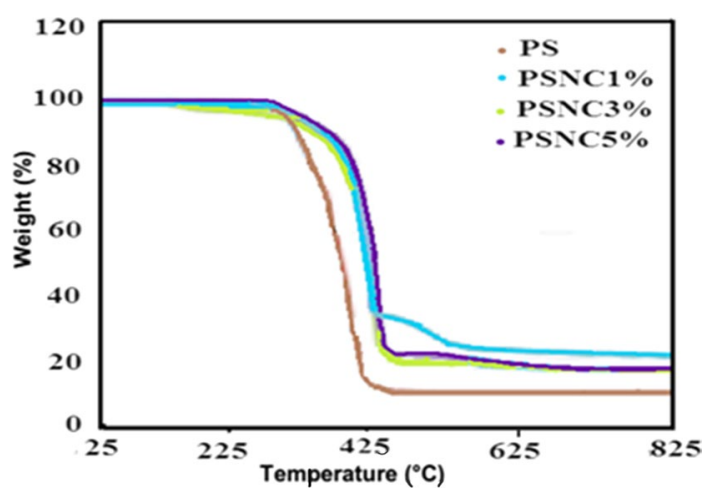

adding $1 \%$ by weight of clay. Chen et al. [36] observed the increase in this temperature by $11{ }^{\circ} \mathrm{C}$ by adding $5 \%$ weight of clay modified by CTA. Some authors have also studied the effect of the way PS nanocomposites are prepared on their thermal properties. Chigwada et al. [37] observed that the thermal stability of the PS was improved when the modified clay was added during mass polymerization compared to the melt mixing method. One possible interpretation is the formation of carbonaceous structures that limit diffusion phenomena. It also appears that optimal stabilization is obtained for charging rates ranging from 2.5 to $5 \%$ by mass. The results showed that the PS/maghnite-CTA nanocomposites had better thermal stability.

The gain in stability of modified PS-clay nanocomposites is due to the formation of a carbonized protective layer. The formation of this layer is stimulated by the fine dispersion of intercalated or exfoliated montmorillonite particles that act as an inorganic carrier [38]. It is important to note that the TGA trace recorded on the PSNC material indicates that the onset of PS decomposition is about $350{ }^{\circ} \mathrm{C}$ higher and the rate of polymer matrix degradation in these nanocomposites is significantly reduced. Indeed, the degradation temperature of the polymers is often improved by the incorporation of silicates in the exfoliated layers [39, 40], which increases the value of these polymers and allows them to be used at higher temperatures.

\section{Mechanical properties}

Charpy test results are shown in Fig. 10. There is a positive trend in the polystyrene/ Mag-CTA curve containing \% maghnite by mass. This tells us that the reinforcement of the polystyrene with modified clay makes the polystyrene stronger and this increase is mainly due to better interface/adhesion loading of the matrix and good dispersion of the load in the polystyrene matrix.

As shown in Fig. 11, the stiffness increases with the filler content of the PSCN\% nanocomposites. This increase is mainly due to better interface between polystyrene and clay adhesion due to good dispersion of the clay load in the polystyrene matrix. These results are in good agreement with those found by 


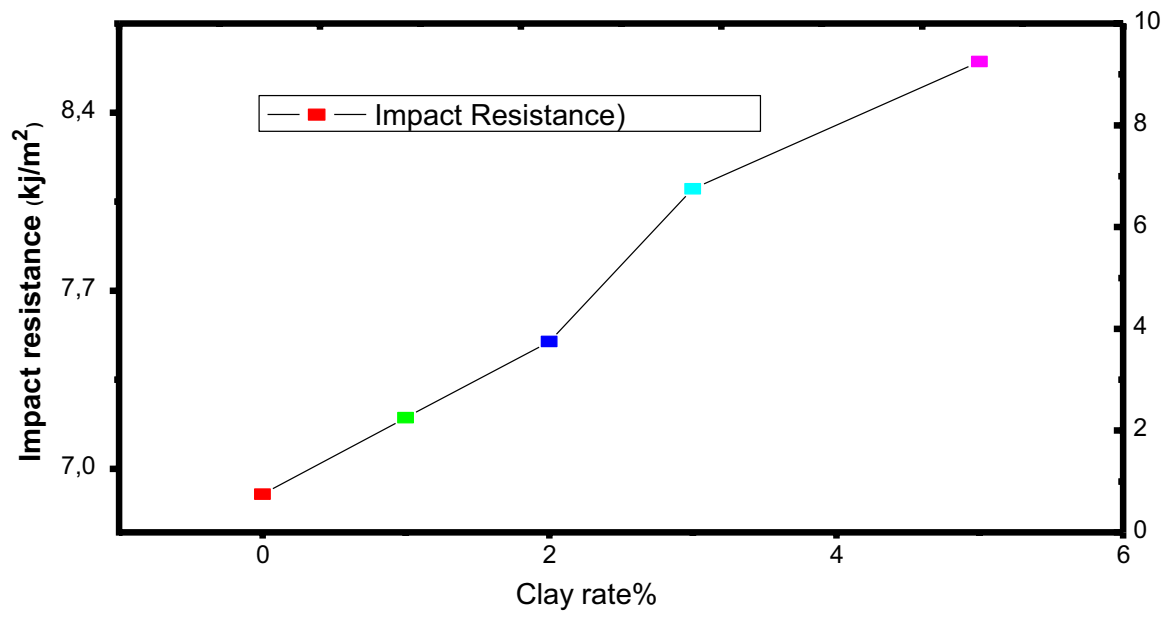

Fig. 10 Influence of Mag-CTA loading rate on the resilience of PSNC nanocomposites

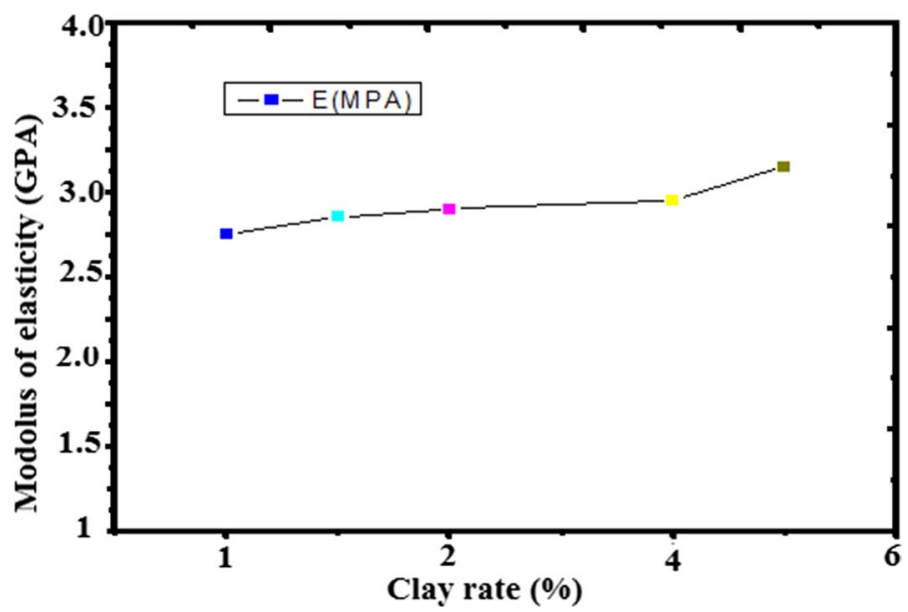

Fig. 11 Evolution of the Young's modulus as a function of the charge rate\% (Mag-CTA)

Uthirakumar et al. [41] who reported a 50\% improvement in Young's modulus by adding 5\% weight of clay to the PS in solution. The addition of organically modified maghnite to polystyrene results in a significant improvement in the Young's modulus of the matrix. It has been found that the increase in modulus is greater for exfoliated nanocomposites. 


\section{Conclusion}

This work made it possible to prepare modified polystyrene-clay nanocomposites using different quantities of organoclays ranging from 1 to $15 \%$ using the in situ polymerization technique. The characterization of the organoclays by different analyses (IR, ATG and DRX, SEM, TEM, AFM) made it possible to quantify the quantity of surfactants incorporated in the clay and the spacing between the clay layers. X-ray diffraction analyses have shown that the majority of the nanocomposites obtained have an exfoliated morphology and the nanocomposites prepared with $15 \%$ by mass of Mag-CTA are of the intercalated type; however, the TEM and SEM images obtained are consistent with the DRX data. The mass polymerization technique has shown the positive effect of the introduction of a cetyltrimethylammonium bromide chain on the thermal stability of nanocomposites. The presence of organically modified maghnite in the polystyrene significantly improves the Young's modulus of the matrix and makes it more resistant. Therefore, a relatively flexible polystyrene-type matrix reinforced with such fillers becomes mechanically very strong, and the maghnite silicate layers, which have a very high specific surface area, bring considerable improvements in Young's modulus. The results obtained showed that Algerian clay can be used as a reinforcement for the development of polystyrenebased nanocomposites.

Open Access This article is licensed under a Creative Commons Attribution 4.0 International License, which permits use, sharing, adaptation, distribution and reproduction in any medium or format, as long as you give appropriate credit to the original author(s) and the source, provide a link to the Creative Commons licence, and indicate if changes were made. The images or other third party material in this article are included in the article's Creative Commons licence, unless indicated otherwise in a credit line to the material. If material is not included in the article's Creative Commons licence and your intended use is not permitted by statutory regulation or exceeds the permitted use, you will need to obtain permission directly from the copyright holder. To view a copy of this licence, visit http://creativecommons.org/licen ses/by/4.0/.

\section{References}

1. Zabihi O, Ahmadi M, Nikafshar S, Preyeswary KC, Naebe M (2018) A technical review on epoxyclay nanocomposites structure properties and their applications in fiber reinforced composites. Compos Part B Eng. https://doi.org/10.1016/j.compositesb.2017.09.066

2. Chen J, Liu B, Gao X, Xu D (2018) A review of the interfacial characteristics of polymer nanocomposites containing carbon nanotubes. RSC Adv. https://doi.org/10.1039/C8RA04205E

3. Tan B, Thomas NL (2016) A review of the water barrier properties of polymer/clay and polymer/ graphene nanocomposites. J Membr Sci. https://doi.org/10.1016/j.memsci.2016.05.026

4. Msaadi R, Ammar S, Chehimi MM, Yagci Y (2017) Diazonium-based ion-imprinted polymer/clay nanocomposite for the selective extraction of lead (II) ions in aqueous media. Eur Polym J. https:// doi.org/10.1016/j.eurpolymj.2017.02.029

5. Feng X, Zhang G, Zhuo S, Jiang H, Shi J, Li F, Li H (2016) Dual Responsive shape memory polymer/clay nanocomposites. Compos Sci Technol. https://doi.org/10.1016/j.compscitech.2016.04.008

6. Zare Y, Fasihi M, Rhee KY (2017) Efficiency of stress transfer between polymer matrix and nanoplatelets in clay/polymer nanocomposites. Appl Clay Sci. https://doi.org/10.1016/j.clay.2017.03.043 
7. Cherifi Z, Boukoussa B, Zaoui A, Belbachir M, Meghabar R (2018) Structural, morphological and thermal properties of nanocomposites poly(GMA)/clay prepared by ultrasound and in-situ polymerization. Ultrason Sonochem. https://doi.org/10.1016/j.ultsonch.2018.05.027

8. Mykola S, Olga N, Dmitry M (2016) The influence of alkylammonium modified clays on the fungal resistance and biodeterioration of epoxy-clay nanocomposites. Int Biodeterior Biodegradation. https ://doi.org/10.1016/j.ibiod.2016.03.021

9. Hosseinabadi HG, Khederlou Kh, Payandehpeyman J, Bagheri R (2016) On variations of the interphase thickness and the slope of strengthening by clay addition in exfoliated polymer- clay nanocomposites. Polymer. https://doi.org/10.1016/j.polymer.2016.03.021

10. Boukoussa B, Abidallah F, Abid Z, Talha Z, Taybi N, Sid El Hadj H, Ghezini R, Hamacha R, Bengueddach A (2017) Synthesis of polypyrrole/Fe-kanemite nanocomposite through in situ polymerization: effect of iron exchange, acid treatment, and $\mathrm{CO}_{2}$ adsorption properties. J Mater Sci. https:// doi.org/10.1007/s10853-016-0541-0

11. Pedreira-Segade U, Michot LJ, Daniel I (2018) Effects of salinity on the adsorption of nucleotides onto phyllosilicates. Chem Phys. https://doi.org/10.1039/C7CP07004G

12. Honorio T, Brochard L, Vandamme M, Lebée A (2018) Flexibility of nanolayers and stacks: implications in the nanostructuration of clays. Soft Matter. https://doi.org/10.1039/C8SM01359D

13. Dike AS, Yilmazer U (2019) Improvement of organoclay dispersion into polystyrene-based nanocomposites by incorporation of SBS and maleic anhydride-grafted SBS Journal of Thermoplastic. Composites. https://doi.org/10.1177/0892705719882998

14. Boufatit MM, Ait-Amar H, Mc Whinnie WR (2008) Development of an algerian material montmorillonite clay-Intercalation with selective long chain alkylammonium cations (Octadecytrimethylammonium, Cetylpyridium and Tetrabutylammonium) and with tellerium complexes Development of an algerian material montmorillonite. Desalination. https://doi.org/10.1016/j.desal.2007.01.204

15. Reguieg F, Ricci L, Bouyacoub N, Belbachir M, Bertoldo M (2019) Thermal characterization by DSC and TGA analyses of PVA hydrogels with organic and sodium MMT. Polym Bull. https://doi. org/10.1007/s00289-019-02782-3

16. Haoue S, Derdar H, Belbachir M, Harrane A (2020) Polymerization of ethylene glycol dimethacrylate (EGDM), using an algerian clay as eco-catalyst (Maghnite-H+ and Maghnite-Na+). Bull Chem React Eng Catal. https://doi.org/10.9767/bcrec.15.1.6297.221-230

17. Mrah L, Meghabar R (2020) Influence of clay modification process in polypyrrole-layered silicate nanocomposite. SN Appl Sci. https://doi.org/10.1007/s42452-020-2338-7

18. Mrah L, Meghabar R, Belbachir M (2015) In situ polymerization of styrene to produce poly styrene /montmorillonite nanocomposites. Chem Reac Catal Eng Bull. https://doi.org/10.9767/bcrec 10.3.8708.249-255

19. Deitzel JM, Kleinmeyer J, Harris D, BeckTan NC (2001) The effect of processing variables on the morphology of electrospun nanofibers and textiles. Polymer. https://doi.org/10.1016/S0032 $-3861(00) 00250-0$

20. Akelah A, Rehab A, Abdelwahab M, Betiha MA (2017) Synthesis and thermal properties of nanocomposites based on exfoliated organoclay polystyrene and poly(methylmethacrylate). Nanocomposites. https://doi.org/10.1080/20550324.2017.1316599

21. Xie W, Hwu JM, Jiang GJ, Buthelezi TM, Pan WP (2004) A study of the effect of surfactants on the properties of polystyrene nanocomposites-montmorillonite. Polym Eng Sci. https://doi.org/10.1002/ pen. 10018

22. Vicente-Rodriguez MA, Suarez M, Banares-Munoz MA, Lopez-Gonzalez JD (1996) Comparative study of removal of octahedral cation and structural modification during acid treatment of several silicates. Spectrochim Acta Part A Spectrosc Mol Biomol. https://doi.org/10.1016/S0584 $-8539(96) 01771-0$

23. Moustafa H, RabeeLawandy MSN, Zahran MAH (2020) Effect of green modification of nanoclay on the adhesion behavior of EPDM rubber to polyester fabric. Int de l'adhésion et des adhes. https:// doi.org/10.1016/j.ijadhadh.2020.102617

24. Zaghouane-Boudiaf H, Boutahala M (2011) Preparation and characterization of organo- montmorillonites. application in adsorption of the 2, 4, 5-trichlorophenol from aqueous solution. Adv Powder Technol. https://doi.org/10.1016/j.apt.2010.10.014

25. Dike AS, Yilmazer U (2020) Mechanical, thermal and rheological characterization of polystyrene/ organoclay nanocomposites containing aliphatic elastomer modifiers. Mater Res Express. https:// doi.org/10.1088/2053-1591/ab66ff 
26. Yu WH, Ren QQ, Tong DS, Zhou CH, Wang H (2014) Clean production of CTAB-montmorillonite: formation mechanism and swelling behavior in xylene. Appl Clay Sci. https://doi.org/10.1016/j. clay.2014.06.007

27. Zhang J, Jiang DD, Wilkie CA (2006) Polyethylene and polypropylene nanocomposites based on a three component oligomerically-modified clay. Polym Degrad Stab. https://doi.org/10.1016/j.polym degradstab.2005.02.004

28. Zhang J, Wilkie AC, Wilkie CA (2006) Polyethylene and polypropylene nanocomposites based on polymerically modified clay containing alkylstyrene units. Polymer. https://doi.org/10.1016/j.polym er.2006.06.018

29. Xing W, Yang W, Yang W, Hu Q, Si J, Lu H, Yang B, Song L, Hu Y, Yuen RKK (2016) Functionalized carbon nanotubes with phosphorus- and nitrogen-containing agents: effective reinforcer for thermal, mechanical, and flame-retardant properties of polystyrene nanocomposites. ACS Appl Mater Interfaces. https://doi.org/10.1021/acsami.6b06864

30. Morgan AB, Gilman JW (2003) Characterization of polymer-layered silicate (clay) nanocomposites by transmission electron microscopy and X-ray diffraction: a comparative study. J Appl Polym Sci. https://doi.org/10.1002/app.11884

31. Akelah A, Rehab A, Agag AT, Betiha M (2007) Polystyrene nanocomposite materials by in situ polymerization into montmorillonite-vinyl monomer interlayers. J Appl Polym Sci. https://doi. org/10.1002/app. 25262

32. Yilmazer U, Ozden G (2006) Polystyrene-organoclay nanocomposites prepared by melt intercalation, in situ, and masterbatch methods. Polym Compos. https://doi.org/10.1002/pc.20191

33. Zang Y, Xu W, Qiu D, Chen D (2008) Synthesis characterization and thermal stability of different polystyryl quaternary ammonium surfactants and their montmorillonite complexes. Thermochim Acta. https://doi.org/10.1016/j.tca.2008.04.017

34. Essawy HA, Badran AS, Youssef AM, Hakim A (2004) Polystyrene/montmorillonite nanocomposites prepared by in situ intercalative polymerization: influence of the surfactant type macromolecular. Chem Phys. https://doi.org/10.1002/macp.200400227

35. Zanga Y, Xu W, Qiu D, Chen D, Chen R, Su S (2008) Synthesis, characterization and thermal stability of different polystyryl quaternary ammonium surfactants and their montmorillonite complexes. Thermochim Acta. https://doi.org/10.1016/j.tca.2008.04.017

36. Chen G, Liu S, Chen S, Qi Z (2001) FTIR spectra thermal properties and dispersibility of a polystyrene/montmorillonite nanocomposite. Macromol Chem Phys. https://doi.org/10.1002/15213935(20010401)

37. Chigwada G, Jash P, Jiand DD, Wilkie CA (2005) Synergy between nanocompositeformation and low levels of bromine on fire retardancy in polystyrenes. Polym Degrad Stab. https://doi. org/10.1016/j.polymdegradstab.2004.12.002

38. Vaia RA, Price G, Ruth PN, Nguyen HT, Lichtenhan J (1999) Polymer/layered silicate nanocomposite as high performance ablative materials. Appl Clay Sci. https://doi.org/10.1016/S0169 -1317(99)00013-7

39. Zhu ZK, Yang Y, Yin J, Wang XY, Ke YC, Qi ZN (1999) Preparation and properties of organosoluble montmorillonite/polyimide hybrid materials. J Appl Polym Sci. https://doi.org/10.1002/ (SICI) 1097-4628(19990912)73:11<2063:AID-APP1>3.0.CO;2-Q

40. Wang S, Long C, Wang X, Li Q, Qi Z (1998) Synthesis and properties of silicone rubber/organomontmorillonite hybrid nanocomposites. J Appl Polym Sci. https://doi.org/10.1002/(SICI)10974628(19980822)69:8<1557:AID-APP10>3.0.CO;2-S

41. Uthirakumar P, Hahn YB, Nahm KS, Lee YS (2007) Exfoliated high-impact polystyrene/MMT nanocomposites prepared using anchored cationic radical initiator-MMT. Hybrid J Eur Polym. https ://doi.org/10.1016/j.eurpolymj.2005.01.017

Publisher's Note Springer Nature remains neutral with regard to jurisdictional claims in published maps and institutional affiliations. 


\section{Affiliations}

\section{Lahouari Mrah $^{1}{ }^{\mathbb{D}} \cdot$ Rachid Meghabar $^{1}$}

$\triangle$ Lahouari Mrah

lmrah@yahoo.fr

1 Laboratory of Polymer Chemistry, Department of Chemistry, Faculty of Exact and Applied Sciences, University of Oran1 Ahmed Benbella, 31100 Oran, Algeria 